\title{
La poesía de Tomás Harris: Una narración a contrapelo*
}

\author{
Harris' poetry: A narrative against the grain
}

MarY MaC-Millan

Universidad Adolfo Ibáñez. Chile

mary.macmillan@uai.cl

T omás Harris ${ }^{1}$ es un poeta y sus libros, mediante el título poesía inscrito en ellos, llaman al lector a sellar el "pacto" de lectura de éstos como poesía. ¿Por qué nos obstinamos en sellar un nuevo pacto y leer la poesía desde un marco genérico desplazado, tal es el de las teorías sobre la narración? Primero, porque esta posible lectura está inscrita en el texto mismo: es el propio tejido y la estructura de estos poemas los que apelan a una lectura distinta. Y segundo, porque creemos (y procuraremos mostrarlo) que una lectura así puede hacer hablar al texto más ricamente que una lectura más canónica.

En relación a la "inscripción narrativa" en la poesía de Harris, basta un vistazo somero a los índices de cada uno de sus poemarios para percibir de inmediato la presencia de estas estructuras. En Cipango, los poemas se agrupan bajo un título que semánticamente actúa como elemento de coherencia: "Zonas de peligro", "La forma de los muros", "Diario de navegación", "El último viaje" y "Cipango". Al interior de "Zonas de peligro" encontramos la técnica de la seriación, la que se mantiene como recurrente en sus libros posteriores. Es decir,

\footnotetext{
* Este trabajo es parte del proyecto de investigación Fondecyt No 11075019, titulado Constitución de un sujeto sobreviviente en la poesía de Tomás Harris: Trauma, cuerpo y narración.

${ }^{1}$ Tomás Harris (nacido en 1956) se ubica dentro de la generación del ochenta y cuenta con una vasta producción poética, la que consta hasta el momento de los siguientes poemarios: Zonas de peligro (1985), Diario de navegación (1986), El último viaje (1987), Alguien que se sueña, Madame (1987), Noches de brujas y otros hechos de sangre (1993), Cipango (1992), Los siete náufragos (1993), Crónicas maravillosas (1996), Encuentros con hombres oscuros (2001), Itaca. (2001), Tridente (2005) y Lobo (2007). A esto se le suma Historia personal del miedo (1994) (cuentos). Ha sido reconocido con los siguientes premios: Premio Municipal de Poesía 1993 por Cipango, Premio del Consejo del Libro y la Lectura 1993 por Los siete náufragos, Premio Pablo Neruda en 1995, Premio Casa de las Américas en 1996 por Crónicas maravillosas y finalista del Premio Altazor con Encuentros con hombres oscuros.
} 
nuevamente conjuntos de poemas agrupados ya sea mediante numeración o por el hecho de compartir el mismo título. Tal es el caso del grupo de poemas "Hotel King", mediante la serie "Hotel King I", "Hotel King II" y "Hotel King III". Lo mismo sucede con "Orompello", esta vez del I al V. Con "Zonas de peligro" no hay numeración sino que encontramos siete poemas, con título homónimo, repartidos a lo largo de la primera parte (páginas 29, 31, 33, 41, $44,49,50)$. Sólo el último poema lleva entre paréntesis el agregado de "Final". Es decir, queda así establecida la ligazón entre los seis poemas, mientras que "Final" debe leerse de manera retroactiva a la luz de los poemas anteriores. ¿No son acaso estos procedimientos de seriación, aunque en apariencia débiles, un principio narrativo al modo en que lo entiende Ricoeur (2004)?2. En estos poemas hay en efecto un entramado, algo que los une y que los presenta ante los ojos del lector como un todo: hay un comienzo, un intermedio y un fin. Decíamos que esta estructura de seriación, ya sea mediante la numeración o el título homónimo, es una constante en su poesía.

Un recurso que Harris también expropia de la narración es el uso de títulos que corresponden deliberadamente a tipos narrativos. Por ejemplo, y para seguir con el índice de Cipango, "Diario de navegación". El diario pertenece al tipo discursivo de la narración y, además, posee por su rasgo de "fechación" el elemento serial y de sucesión por excelencia, es decir, es un relato de acontecimientos. Otro título narrativo: "El último viaje". El viaje es por antonomasia el origen de las narraciones orales.

En el libro Los siete náufragos se repiten las estructuras narrativas aplicadas a los poemas. Tal es el caso del apartado IV: "Cartas de relación de la desfundación de una ciudad”. Nuevo envío mediante alusión al género. Y más, el capítulo cinco: "La relación del cinocéfalo herido de muerte". Al título de "relación" se le suma al interior el recurso de la seriación: los poemas no tienen título sino números. Más ejemplos del recurso del nombre descubrimos en su tercer poemario, Crónicas maravillosas. Se trataría, entonces, de "crónicas" y no de poemas, un género que al igual que los relatos y los diarios destaca por su primacía temporal y su sucesión. En este libro, los guiños son evidentes: "Fragmento de la crónica que dejara Alvar Nuño Cabeza de Vaca antes de huir con 7 indias de bronce con las cuales amancebóse y cambióse el nombre a Gaspar Ilóm y tuvo 7 crías quedando así en condición de bárbaro blanco en medio de la nada y el todo". Si hemos transcrito el largo título de, nótese, un

${ }^{2}$ Nos referimos a las teorías sobre la narración y la trama expuestas por Paul Ricoeur en su obra Tiempo y narración (2004). Requisito básico de toda trama es la configuración interna y el grado de coherencia entre principio, medio y fin. 
"poema”, es para recalcar cómo Harris extrema su recurso, ya que este título en sí, no sólo alude temáticamente al género de la crónica, sino que su forma corresponde a una mínima crónica o relato. El título contiene el relato en germen entendido como acontecimientos: "huir", "amancebóse", "cambióse", "tuvo crías" y "quedando". Tenemos todo lo que exige Ricoeur (2004) para una narración: comienzo, medio y fin, además del cambio y la transformación del héroe. A estas alturas se entiende que la presencia de estructuras narrativas en la poesía de Harris, no es mero adorno o salpicado, sino que obedece a algo más profundo y es una constante que nos permite considerarla una estructura.

Otro recurso narrativo es el de la presencia de un "personaje" que actúa como hilo conductor a través de varios poemas. Para dar algunos ejemplos: En Los siete náufragos, en el conjunto titulado "Kurtz remonta el río", cada poema mantiene a Kurtz como sujeto de las acciones: Kurtz huye, Kurtz ensueña, Kurtz cambia, Kurtz ruega clemencia, etc. En Crónicas maravillosas encontramos más "personajes" centrales de hazañas: el almirante Antonius Block, el nombrado Alvar Nuño Cabeza de Vaca, etc. Ya en el cuarto poemario podríamos esperar un giro en las técnicas mencionadas, mas lo que se halla es, por el contrario, una exacerbación. Ítaca reúne siete minirelatos centrados en un tema bien establecido: "La balsa de la medusa" con el personaje de Géricault; "El Minotauro sin su laberinto", centrado en Teseo; "El hombre de visión de rayos", centrado en Ray Milland; "El hombre sin brazos", en Lon Chaney; "Blue velvet", traspaso a palabras del filme de David Lynch; (Dix)inoario, especie de biografía del pintor Otto Dix; y, finalmente, "Ítaca". Es decir, Itaca es un texto íntegramente estructurado como una colección de relatos, los que a su vez tienen como base intertextual ya sea un relato histórico, fílmico o literario. Tridente, sexto poemario de Harris, continúa en el mismo tono y con semejantes recursos. Esta vez se trata de tres series de poemas. El primero, "Edipo Androide en la blanca Colono", se centra en el género de la carta y consiste en un intercambio epistolar entre Edipo y Aurelia. El segundo diente de esta triada se titula "Balada del condenado de Oklahoma" y gira en torno a la Guerra del Golfo. Finalmente, "Las jornadas del sordo" se estructura de modo secuencial y da cuenta del trabajo pictórico de Goya.

Una técnica narrativa bastante marcada es la de las numerosas alusiones metatextuales a la narración. En Los siete náufragos, por ejemplo, se nos dice: "Por esto narramos, / estamos asidos a un madero / (...) por eso narramos, / sólo por eso / vamos a narrar" (1995: 7), o, "pocos sobrevivieron para narrarlo". A veces, el énfasis da un giro y se nos presenta, ya no como narración, sino como película, hecho que para nuestros efectos da lo mismo, ya que se mantiene el 
énfasis en la seriación de acontecimientos: "un gran mar en calma. / Este film es en blanco y negro" (1995: 9).

También destacamos la insistente marcación textual que del propio término o fin del relato se nos ofrece, es decir, la conciencia de la estructura del relato. Prueba de esto es que la mayoría de los poemarios tiene un poema de cierre. Es decir, no se termina meramente con un último poema, sino que este último poema actúa como fin. Aquí tenemos la radical diferencia mencionada por Ricoeur (2004) y también por White (1992) entre terminar y finalizar. El fin implica la conciencia y conexión con los acontecimientos (poemas) precedentes. Algunos ejemplos de esta presencia del fin a nivel metatextual: Crónicas maravillosas cierra con un epílogo, Itaca concluye con el poema "Los adioses", Los siete náufragos termina con la sentencia "El que entienda mariposa, que entienda". Numerosas series de relatos acaban con poemas titulados "The End".

Otro recurso que liga la poesía de Harris a la narración es la "traducción intermedial" desde el cine o la pintura. Es decir, numerosos poemas o grupos seriados de poemas consisten en un relato ya sea de una película o de un cuadro. Hay un transbordo de un relato fílmico al de uno propiamente narrativo, tal es el caso de "Blue velvet" de Ítaca, en el que se nos refiere la película homónima de David Lynch. El mismo procedimiento hallamos en la "narración" de algunos famosos cuadros de El Greco, Otto Dix y Géricault. Aquí, lo estático, la imagen pictórica, se vuelve movimiento y en una suerte de metalepsis al revés deviene historia y sucesión de acontecimientos. Es lo que sucede en "Asesinato de placer" (I, II y III), serie que toma como base el cuadro de Otto Dix: "Si miramos, digo, o más bien si se nos obliga, / como en los sueños, / a mirar por el ventanal sangriento, / abierto en un óleo de 165 x 135 milímetros, / la escenografía de la muerte, / al centro vemos cadáver, / medio cuerpo sobre la cama" (2001: 151). Similar proceso de narrativización sufren los cuadros de Goya ("El coloso entre las nubes", "Perro semihundido", "El fusilamiento") y de Géricault ("La balsa de la medusa"). Vemos en estos procesos que hemos denominado de "traducción intermedial" una pulsión por narrar. Si Primo Levi (2006) dividía a aquellos que callan de aquellos que hablan (narran), definitivamente Harris pertenece al segundo grupo. Sus procedimientos consisten en una especie de fagocitación narrativa, ya que todo se convierte en relato y es subsumido en su escritura: relatos fílmicos, cuadros, historias escuchadas (el caso de los relatos de su padrastro en "El soldado alemán Erwin Kopp regresa del frente italiano"), noticias de la prensa (Balada del condenado de Oklahoma en Tridente); otras narraciones ya sea literarias o históricas (crónicas del descubrimiento, libros de aventuras, etc). Quizás el más claro ejemplo de esto es el título de su penúltimo poemario "Encuentros con 
hombres oscuros", es decir, un relato fílmico (Encuentros con hombres notables) le sirve para denominar su propio poema-relato.

Resumamos, hemos sostenido que una lectura de la poesía de Tomás Harris desde las teorías de la narración no es mero capricho nuestro, sino que es una demanda que se haya inscrita en el tejido mismo de esta escritura. Hemos reconocido al menos seis procedimientos o técnicas que avalan esta lectura: 1 . La seriación de poemas que se presentan así de manera cohesionada y que se leen por lo mismo como un relato. 2. Los títulos tomados de géneros propiamente narrativos, tales como "diario", "crónica", "relato". 3. La utilización de un personaje que se repite y actúa como marca isotópica en una cadena de poemas. 4. Constantes alusiones metatextuales a que se está narrando. 5. Los numerosos poemas que fungen como fin de una serie y que se marcan expresamente con un título alusivo al fin. 6. La traducción intermedial que se revela como una obsesión generalizada.

Basten de momento estas observaciones para afirmar nuestra lectura: que la narración no es sólo un elemento tangencial o de adorno en la escritura harriana, sino que es el fundamento y la estructura misma de su poesía. Y más aún, y a esto nos abocamos en los análisis siguientes, de esta opción emana el sentido mismo y la originalidad de dicha escritura. A continuación ofrecemos un análisis ${ }^{3}$ a modo de ejemplo: "Encuentros al fin de la batalla".

\section{"Encuentros al fin de la batalla"}

Según Walter Benjamin el soldado vuelve mudo de la batalla, según Primo Levi (2006) los sobrevivientes se dividen en los que hablan y los que callan. En el largo conjunto de poemas "Encuentros al fin de la batalla" (Harris, 2001a), leemos una afirmación de la postura de Levi: se puede comunicar una experiencia y, más aún, hay quienes pueden "escuchar" esa experiencia. El "escuchador" de los relatos de guerra es Tomas Harris niño, quien presta oído a las historias que su padrastro Erwin Kopp, ex soldado alemán, le cuenta de su adolescencia. Es decir, los poemas se enmarcan al interior de una situación narrativa: "la cosa es que crecí, algunos años de mi vida, junto a él, y ya en mi adolescencia, algunas cervezas mediante, comenzó poco a poco a hablarme de la guerra. Por supuesto que le costaba, pero no sé por qué vio en mí a un escuchador válido" (Harris, 2001a: 86-87). Se trata de una situación narrativa

\footnotetext{
${ }^{3}$ Por motivos de espacio en esta nota hemos escogido un análisis, en la investigación total abordamos, además ,"Una ínfima hecatombe", "Sueño", "El hombre sin brazos", "Las jornadas del sordo" y "Crónicas maravillosas".
} 
enmarcada en un diálogo, un yo sobreviviente le cuenta, traspasa experiencias a un tú que es receptivo. Ahora bien, ¿qué hace el escuchador? Elabora a su vez un nuevo relato, poemas que dan cuenta de la primera narración. Los poemas están en el lugar de la experiencia, los poemas "narran", es decir, "transmiten una experiencia". Recordemos la distinción benjaminiana de narración versus información. La narración se inscribe dentro del marco de la tradición oral, en la que se transmite, junto con la historia, un saber. En el caso de la guerra, para Benjamin sería el "acontecimiento sin testigos" (para ocupar una nomenclatura de Agamben) o un acontecimiento que se resiste a entrar en el relato: los soldados vuelven mudos. Los textos de Harris son, entonces, la enconada y doble resistencia a esta supuesta mudez: habla el soldado y poetiza el joven que escucha al soldado. Veamos ahora qué experiencia porta la poesía en cuestión.

Nos centramos en el análisis de tres poemas seriados: "Regreso a casa" (Primera versión), "Regreso a casa" (Segunda versión) y "Regreso a casa" (Tercera versión). Esta vez la ya clásica seriación adquiere una innovación, son versiones ${ }^{4}$, como si un nudo permaneciera no dicho y se insistiera majaderamente en volver a él. Leído así es mucho más evidente el intento de comunicar una experiencia, de hacerla transmisible. Ya no es sólo una serie que indica temporalidad o secuencia, sino un gesto de búsqueda, la palabra que vuelve sobre sí misma hasta que se haya dicho lo que había que decirse. Así leemos el término "versión". Hay siempre más versiones, más posibilidades de decir lo indecible. ¿Cuál es el núcleo de esta experiencia?: los cruces temporales que afectan a la subjetividad. Un joven que vuelve de la guerra y ya no es el mismo. Pero no sólo él ha cambiado, también el espacio al que regresa (el hogar). Los cruces temporales se dan entre el sujeto que era y el que es, el hogar que era y el que es, y las posibilidades de encuentros o desencuentros mutuos.

La Primera versión se abre con el siguiente verso: "Bienvenido a casa" (Harris, 2001a: 92). El joven soldado inicia un reconocimiento de su entorno. Parte por los objetos y la constatación de que siguen ahí: "revisa tus objetos, sobre todo los azules, tus botas, tus chaquetas viejas" (2001a: 92). Aún no se nos dice el resultado de la re-visión. Pero está claro que el acto contiene la constatación de un antes y un después. Los objetos "suyos" antes de la guerra y esos "mismos" después de la guerra. Luego, la "re-visión" se dirige ahora hacia la naturaleza: "el ruido de la frondosidad de los olmos cuando todavía no los habíamos talado para lograr un poco de lumbre" (2001a: 92). Hay ya

${ }^{4} \mathrm{El}$ recurso a las versiones parece provenir de Georg Trakl, mas en Harris son poemas distintos, en el caso de Trakl (1994) es un mismo poema con cambios o retoques. A modo de ejemplo, ver el poema "ocaso", el que tiene cuatro versiones. 
el asomo de una "pérdida", de una diferencia: el bosque ha sido talado, no es el mismo. Continuamos: "ahora estamos en un círculo milagroso en torno a la hoguera". Es el espacio perfecto para que advenga el "relato oral", la narración según Benjamin al calor de la hoguera y la predisposición anímica. Más lo que viene es la mirada acuciosa que todo lo tasa y lo sopesa: "Miro todo lo que alcance el radio de la lumbre" (2001a: 92). Y, finalmente, adviene el deseo de la sustitución. El joven soldado que ha sometido a revisión sus objetos y su entorno, frente a la aparición de una rata negra, ofrece: "rata negra cambiemos de piel; yo te regalo mis viejas prendas y tú me das tu inmortal inconsciencia" (2001a: 92). ¿Qué es lo que está en juego en este extraño cambalache? ¿Qué es lo que se permuta? Pues lo central de la experiencia del regreso: la conciencia del paso del tiempo y su poder devastador. Sólo en este último verso podemos vislumbrar retroactivamente el juicio del resultado de la re-visión, el resultado es negativo: el joven ha pasado por la experiencia de la muerte y ha envejecido; la rata posee la inmortalidad. Inmortalidad entendida como la ignorancia del tiempo y de su herida. La herida del soldado no es tanto la de la guerra en sí, sino la del regreso y la constatación de la pérdida del hogar. Se vuelve a lo conocido y, sin embargo, distinto. Esa escisión temporal del antes y el después y el desastroso ahora es lo que se desea permutar en la "inmortal inconsciencia" de la rata.

Pasemos a la Segunda versión. Esta versión la podemos entender como una especie de retorno, de re-visión y de vuelta atrás. Es la repetición, como la entiende Ricoeur, en donde se vuelca hacia lo ya acontecido para buscar en él lo que permita abrirse al futuro. Efectivamente, el primer verso de la Segunda versión remite dialógicamente al primer verso de la Primera versión. "Bienvenido a casa" de la Primera versión se entreteje con este otro primer verso: "La bienvenida, ¿de quién?; / o, más bien, ¿¿de qué?"(Harris, 2001a: 93). En este gesto leemos una especie de borradura derridiana tal y como la localizamos en algunos textos posmodernos 5 . Borradura en la medida en que se viene a cuestionar y a poner en duda la sentencia anteriormente afirmada. Si se hablaba de "bienvenida", preciso es preguntarse por el sujeto que la otorga.

${ }^{5}$ El concepto lo extraemos de Brian McHale en Postmodernist fiction (1991). McHale, siguiendo a Derrida, sostiene el estatuto de la borradura como la simultánea presencia y ausencia: "Physically canceled, yet still legible beneath the cancelation, these signs sous rature continue to function in the discourse even while they are excluded from it" (McHale, 1991: 100). Procedimientos narrativos que se dejan adscribir bajo la borradura son variados. Por ejemplo: el "retake" (secuencias son dadas para luego ser negadas), el "excluded middles" (un acontecimiento ocurre y no ocurre al mismo tiempo o un mismo acontecimiento ocurre dos veces pero de modo irreconciliable) y la multiplicación del comienzo y del fin. 
En esta Segunda versión hay un ahondamiento en el quiebre temporal avisado en la primera: el antes y el después de la guerra y su funesta acción y poder de cambio sobre el hogar, lo "conocido" por excelencia. Tanto así que lo heimlich se vuelve unheimlich. Lo propio se tronca en ajeno, desconocido. Se afirma en nueva contradicción o borradura que no se quiere hablar de, más se habla de: "no quiero hablar de la sustitución de las flores por el barro, de las tejas por alambradas de púa, de la puerta por un orificio mudo, como esperando que le arranquen una muela, una tetera o el sofá" (Harris, 2001a: 93). Aquí está patente el cambio y el paso destructor del tiempo. Si la casa no puede, en su cambio, dar la bienvenida al soldado, entonces, los padres. Nueva negación y constatación de cambio: "si Padre y Madre ya han muerto". Más cambios: "yo vi el río seco, o vi sangre en lugar de la cotidiana agua verde de su curso". Hasta aquí el texto no hace más que negar lo que ha afirmado inicialmente: "Bienvenido". Pero, ¿quién da la bienvenida? Debemos concluir que no hay bienvenida, no hay "regreso a casa". El soldado que vuelve de la guerra se transforma en un sobreviviente, se salva de la muerte en el campo de batalla mas no regresa a la vida, queda así en un estatuto intermedio. La "experiencia" a narrar entonces es ésta: la del desarraigo, la del imposible regreso, la de la escisión tanto del tiempo como del sujeto que no se halla en ninguna parte.

La Tercera versión (Harris, 2001a: 94) implica un cambio en el sujeto. Hasta el momento, el soldado revisa y mira su entorno, más ahora es el soldado el observado y sujeto a revisión: "la casa me mira y no me reconoce". Por primera vez en el poema se nos da una marca temporal: ¿Tanto he cambiado en un año? El lapso originador del, ahora lo sabemos, doble cambio (del sujeto y del hogar), es un año. Insistimos en el cambio situado al interior de un vínculo, de una relación. No es que el soldado cambie y el hogar cambie, sino que el soldado cambia para el hogar y éste para el soldado. De ahí el desencuentro. Ahora bien, no es sólo un año sino la "eternidad": "¿tanto varía el gesto en la eternidad de la guerra?” ¿Por qué eternidad si se trata de un tiempo medible? Ante la hostilidad de la casa el soldado apela a un pasado común, pasado en el que la identidad aún existía: "Mira, le digo, soy yo". Ese "soy yo" muestra su propia escisión, ya que apela al pasado, no hay coincidencia entre el presente del "soy" y el predicado mediante el cual se define (los verbos en pretérito de jugar y acariciar): "soy yo el que jugaba escondido en el desván con las muñecas de mi hermana Ingrid, yo que acariciaba el pasamanos cuando bajaba hacia tu vientre a desayunar”. Por más que el soldado intente, en la heterotopía del lenguaje, crear la identidad entre el yo del presente y el yo del pasado, la casa niega esta identidad: "parece que la casa se encogiese". Es decir, no hay reconocimiento, no hay bienvenida, no hay regreso a casa. Ahora bien, ¿̨cuál 
es el resultado de este no reconocimiento para el sujeto? Pues que queda en un estado intermedio, en un presente suspendido en el tiempo: "No sé si avanzar (...) Y tampoco puedo volver mis pasos: no tengo otro lugar adonde ir". El sujeto que retorna de la guerra es un apátrida por excelencia, ha perdido su hogar (pasado) y con él su futuro. Queda así desgarrado y se sitúa en la crisis misma.

Veamos con mayor detenimiento el manejo del tiempo en los poemas en cuestión. Ricoeur (1999) distingue tres niveles o grados de profundidad en el tiempo: temporalidad, historia e intratemporalidad ${ }^{6}$. ¿En cuál de estos tres niveles situamos al sujeto sobreviviente, al soldado que regresa de la guerra? Paradójicamente, en ninguno de los tres. El sujeto no accede a la temporalidad ya que este es un "tiempo para", se "cuenta con él" y es el de la acción propiamente tal. Si bien se nos entrega una sola datación, la del año que se ha estado en la guerra, lo que se viene a poner en duda precisamente es que se trate tan solo de un año y nada más. Si la intratemporalidad es el tiempo de la intervención, pues en el relato-poema se ve a un sujeto impedido de actuar, no puede ni avanzar ni retroceder. Decididamente no cuenta con el tiempo. Historicidad encontramos en la medida en que se mira al pasado, pero este pasado no logra rescatarse para el presente, el sujeto no logra la ligazón en la medida que el pasado queda inconexo de su presente, no le permite la reunión en un yo definido y reconocible por el otro, en este caso la casa. Mucho menos podemos hablar de temporalidad como un vínculo entre los tres éxtasis temporales: pasado, presente y futuro. Lo que hay en las versiones de "Regreso a casa" es primero la imposibilidad del retorno, es decir, se quiebra con el nivel de la historicidad y luego, como resultado de este quiebre, el desprendimiento o anulación del futuro como proyección. Lo que indaga el poema es la "eternidad" o la suspensión de las coordenadas temporales que paralizan al sujeto. El sobreviviente sale de las coordenadas temporales. La experiencia radical de la guerra y la abertura del antes y el después suspenden al sujeto en un ahora que no es lo mismo que un presente. El presente se caracteriza por su conexión con el pasado y el futuro. El tiempo del sobreviviente es el de la expulsión. Se llega así a la radicalidad del acontecimiento a narrar, la guerra es desgarradora y sólo origina un relato que demuestra el doble desgarro del sujeto y del tiempo. ¿Hay un "fin” en el relato de esta vuelta a casa? Una bienvenida podría ser un fin, una consecución lógica o esperada del acto de regresar. Un rechazo y una vuelta a la acción de

${ }^{6}$ La intratemporalidad es el tiempo medible y con el que contamos para actuar. La historicidad es el tiempo del pasado al que recurrimos para conectarlo con nuestro presente. La temporalidad es la unión entre pasado, presente y futuro. Ricoeur se basa en los postulados de Heidegger. 
la guerra también es un fin pausible. ¿Qué hay en esta serie? Un fin que no lo es: un sujeto parado, digamos paralizado, entre el hogar que ya no es tal y un pasado imposible: "tampoco puedo volver mis pasos: no tengo otro lugar adonde ir. Dudo si quedarme aquí de pie, eternamente tal vez o hasta que muera de ruina" (Harris, 2001a: 94). La experiencia de la guerra ha despojado al sujeto de su lugar en la historia, lo ha destituido a su vez de su finalidad, de su capacidad de actuar.

Pensemos ahora en el estatuto de sujeto, ese "resto" que permanece de pie y al que sólo le queda esperar en una espera que no espera. Según Ricoeur (1996), la identidad consta del juego del ipse con el idem ${ }^{7}$. Las narraciones de ficción suelen mostrar a un ipse (quién) sin el apoyo de su idem (carácter). Mas lo que tenemos en el sujeto sobreviviente es aún más extremo: no hay ipse, ya que se ve imposibilitado de actuar debido a la escisión temporal, y tampoco hay idem, ya que sus rasgos (gestos) que lo mantenían en el tiempo como idem le han sido arrebatados por la guerra. El sujeto que vuelve de la guerra ha sido doblemente despojado: primero de su identidad como idem o suma de rasgos que permiten reconocerlo (el sujeto es de hecho irreconocible) y luego de su identidad como ipse o actuante, ya que no puede ni regresar al pasado ni proyectarse al futuro. Llegamos ahora a la paradoja por excelencia, ¿Cómo puede este no-sujeto, doblemente anulado y despojado, dar testimonio de su experiencia? La respuesta es sólo una y es que ese no-sujeto, esa cáscara o cuerpo aún humano, recupera, con el paso del tiempo, al menos una de sus identidades y relata a otro su experiencia límite. Ese sujeto recobrado en y por el relato es, referencialmente hablando, Erwin Kopp y es también, como Harris nos advierte en su introducción, "una figura poética". Es decir, es el relato-poema el que muestra la problemática del sujeto puesto a narrar una experiencia límite: el no-retorno a casa. La posibilidad de la narración o la narración pese a todo es positiva en la medida en que da fe de una subsistencia de un sujeto. No creo poder explicar del todo la paradoja en la que nos movemos, sólo quiero constatar que mientras haya narración habrá algún tipo de sujeto. Puede ser que aquí sea Hannah Arendt quien demuestre tener razón cuando afirma que no es el sujeto de la experiencia el llamado a historiar, sino un narrador externo y con distancia. ¿Es Tomás Harris el sujeto que actúa de historiador y quien le da coherencia a la experiencia muda de la que hablaba Benjamin? En todo caso, hay transmisión de experiencia y eso es

\footnotetext{
${ }^{7}$ Ipse e idem son dos modos de concebir la identidad. Ipse se refiere al sujeto como agente y que responde de sus acciones, se le concibe como un "quién". Idem, por el contrario, es un concepto ligado a un substrato siempre idéntico y no mutable. Es el sujeto como un cúmulo de características y que responde al "qué" (Ricoeur, 1996).
} 
lo que queremos recalcar. Es decir, en "Regreso a casa" en sus tres versiones existe una narración a contrapelo, en la medida en que cuestiona tanto el tiempo como el sujeto postulado por Ricoeur. Sin embargo, y pese a todo, el relato subsiste.

\section{REFERENCIAS}

Agamben, Giorgio. 2000. Lo que queda de Auschwitz. El archivo y el testigo. Valencia: Pre-Textos.

Arendt, Hannah. 1993. La condición humana. Barcelona: Paidós.

Benjamín, Walter. 1991. El narrador. Madrid: Taurus.

Harris, Tomás. 1995. Los siete náufragos. Santiago: RIL. .1996. Cipango. Santiago: F.C.E.

.1997. Crónicas maravillosas. Santiago: Editorial Universidad de Santiago de Chile.

.2001a. Encuentros con hombres oscuros. Santiago: RIL. 2001b. Itaca. Santiago: Lom. 2005. Tridente. Santiago: RIL.

White, Hayden. 1992. El contenido de la forma: narrativa, discurso y representación histórica. Trad. Jorge Vigil Rubio. Barcelona: Paidós.

Levi, Primo. 2006. Si esto es un hombre. Trad. Pilar Gómez Bedate. Barcelona: El Aleph.

McHale, Brian. 1991. Postmodernist fiction. London: Routledge.

Ricoeur, Paul. 1996. Sí mismo como otro. Madrid: Siglo XXI. .1999. Historia y narratividad. Barcelona: Paidós. .2004. Tiempo y narración. México: Siglo XXI.

Trakl, Georg. 1994. Obras completas. Madrid: Trotta. 